\title{
Research and Test on the Principle of Oil Temperature Rise of Pumps with Single and Double Valve Plate
}

\author{
D. S. Wen ${ }^{1}$, J. Wen ${ }^{2}$, X. J. Zhu ${ }^{1}$ \\ ${ }^{1}$ Department of Mechanical Engineering Yanshan University, Qinhuangdao 066004, China \\ ${ }^{2}$ College of Information Science and Engineering, Yanshan University, Qinhuangdao 066004, China \\ Email: wendesheng@ysu.edu.cn
}

\begin{abstract}
Oil temperature rise and cooling of an axial piston pump are of significant factors which affect the service lifetime of the pump. So they are important aspects in the theoretic research of the fluid power pump. Oil temperature rise and cooling existing in the research and test of CY14-1A pump and $25 \mathrm{KZB}$ pump are introduced. The relevant expression and analysis are performed. These two types of pump are tested and the results show that the pump with double valve plate has self-cooling performance and the lubrication between rubbing parts is improved greatly.
\end{abstract}

\section{REFERENCES}

1. Kojima E, et al. Characteristics of fluidborne noise generated by fluid power purnps-1. Mechanism of generation of pressure pulsation in axial piston pump. Bulletin of the JSME, 1982; 25(199): 46-53

2. Mansour A K, et al. Predicting axial piston pump ferformance using neural networks. Mechanism and Machine Theory, 1999; 34: 1211-1226

3. Manring N D, Johnson R. Modeling and Designing a Variable-Displacement Open-Loop Pump. ASME Journal of Dynamic Systems, Measurement, and Control., 1996; 118: 267-271

4. Wen D S. Research on a new type of axial piston pump: an open channel axial piston pump. Chi Hsieh Kung Ch'eng Hsueh Pao/Chinese Journal of Mechanical Engineering, 1987; 23(2): 74-77

5. Wen D S. The pump with double valve plate. Patent No. 851032893. 1985

6. Wen D S. Research on the principle and test of open-loop axial piston pump with double valve plate. Journal of College of Northeast Heavy Machinery, 1984; 2: 1-6

7. Wen D S. The characteristic and application of KZB pump. Hydraulics and Pneumatics, 1988; 48(4): $17-19$

8. Wen D S, et al. Comparison of self-cooling of CY pump and SPB pump. Jixie Gongcheng Xuebao/Chinese Journal of Mechanical Engineering, 2002;38(9):150-154.

9. Wen D S, et al. A new method for reducing temperature of CY pump. Gansu Gongye Daxue Xuebao, 2005; 31(4): 58-61

10. Wen D S, et al. The optimal self-cooling design for the open-circuit axial plunger pump. Machinetol \& Hadraulics, 2004; 9: 201-201,184 